ORIGINAL ARTICLE

\title{
Benthic megafauna on steep slopes at the Northern Mid-Atlantic Ridge
}

\author{
James B. Bell ${ }^{1,2}$, Claudia H. S. Alt ${ }^{3}$ \& Daniel O. B. Jones ${ }^{3}$ \\ 1 The School of Geography, University of Leeds, Leeds, UK \\ 2 Natural History Museum, London, UK \\ 3 National Oceanography Centre, University of Southampton Waterfront Campus, Southampton, UK
}

\begin{abstract}
Keywords
Deep sea; hard substrata; image analysis; megafauna; Mid-Atlantic Ridge; Porifera.

\section{Correspondence}

James B. Bell, The School of Geography, University of Leeds, Leeds LS2 9JT, UK.

E-mail: gyjbb@leeds.ac.uk
\end{abstract}

Accepted: 6 June 2015

doi: $10.1111 /$ maec. 12319

\begin{abstract}
The role of small-scale $(<10 \mathrm{~km})$ habitat availability in structuring deep-sea hard substratum assemblages is poorly understood. Epibenthic megafauna and substratum availability were studied on steep slopes at the Mid-Atlantic Ridge from May to July 2010 northwest, northeast, southwest and southeast of the Charlie-Gibbs Fracture Zone (CGFZ; 48-54 $\mathrm{N}$ ) at between 2095 and $2601 \mathrm{~m}$ depth. Megafauna were six times denser north of the CGFZ compared with the south and differences in density were almost entirely driven by sessile fauna. There was no significant difference in habitat availability amongst sites. Rocky substratum made up $48 \%$ of the total area surveyed, with individual transects having between $0 \%$ and $82 \%$ rock. Assemblage structures were different amongst all superstations. The north was dominated by demospongids and hexactinellids, whereas the southern superstations were dominated by anthozoans and hexactinellids. Differences in megafaunal assemblages north and south of the CGFZ primarily reflected variations in demospongid and anthozoan species composition. With 213-1825 individuals.ha ${ }^{-1}$, and 7-24 species per superstation, hexactinellids were the most species-rich (36 species) and cosmopolitan taxa at the study site, supporting observations elsewhere along the ridge and in the CGFZ. The absence of significant differences in substrata availability suggested alternative drivers for density or percentage cover. The amount of hard substratum available only limited sessile megafauna density at one transect that was entirely covered with sediments. Species richness was highest for areas with intermediate values of substratum coverage (35-43\% rock).
\end{abstract}

\section{Introduction}

Fine-scale measurements of spatial heterogeneity, over large areas of sea bed, are crucial to our understanding of benthic biology (Auster et al. 1995), particularly in the case of vulnerable marine ecosystems, such as areas of the Mid-Atlantic Ridge (MAR; Sánchez et al. 2009; BragaHenriques et al. 2013; Kröger 2013; Narayanaswamy et al. 2013). Vulnerable marine ecosystems are largely under threat from deep-water demersal fisheries that target ridges and seamounts (Hareide \& Garnes 2001; Priede et al. 2013; Clark et al. 2014). Many studies focus on habitat-forming properties of sponges or corals (Ross \& Quattrini 2007; Bo et al. 2012; Quattrini et al. 2012; Beazley et al. 2013) without investigating how their physical habitat controls their characteristics (Schneider et al. 1987; Witman et al. 2004; Jones et al. 2013a,b; Narayanaswamy et al. 2013; Purser et al. 2013; Robert et al. 2014). The MAR has large areas of exposed rock (Gebruk \& Krylova 2013), where species distributions may depend upon the balance between hard and soft substrata (Watanabe et al. 2009). Having mixed substrata introduces an extra controlling factor not seen in the purely soft sediment environments typical for the deep sea 
(Kahn et al. 2012). This study fills an important gap in our knowledge of the distribution and extent of benthic megafaunal communities at the northern MAR, complementing other studies carried out at the MAR (Mortensen et al. 2008; Morris et al. 2012; Alt, Rogacheva et al. 2013; Gebruk \& Krylova 2013).

Studies of areas with hard substrata on the North Atlantic continental margins (Sánchez et al. 2009; Watanabe et al. 2009; Wagner et al. 2011) and seamounts (Duineveld et al. 2004; Wienberg et al. 2013) have shown that the presence of hard substrata in the deep sea encourages reef-forming taxa to settle, e.g. scleractinids, hexactinellids and demospongids, which impacts community composition and increases biomass of other fauna, such as fish (Ross \& Quattrini 2007; Quattrini et al. 2012; Beazley et al. 2013). Mid-ocean ridges and seamounts have been identified as areas of elevated benthic secondary productivity (Priede et al. 2013) that are characterized by high habitat heterogeneity, supporting a high diversity of epibenthic fauna (Morris et al. 2012; Gebruk \& Krylova 2013; Wienberg et al. 2013). Variation in seafloor habitat is very important for sessile fauna, with mixed substratum (rock and sediment) supporting different assemblages compared with homogenous areas of rock or sediment (Sánchez et al. 2009; Morris et al. 2012). These changes in the composition of assemblages of sessile marine species are primarily driven by physical habitat complexity, particularly fine-scale variations in water flow (Smith \& Witman 1999; Witman et al. 2004; Palardy \& Witman 2011) that control larval and food supply (Soltwedel et al. 2013), and biological factors, such as larval supply rates and the regional species pool (Witman et al. 2004). The biogeochemical composition of the rocky substratum determines larval selection and attachment processes (Dorschel et al. 2009; Sánchez et al. 2009; Watanabe et al. 2009; Wienberg et al. 2013), with clear local substratum selectivity being exhibited by the larvae of sessile fauna, such as deep-sea alcyonaceans (Sun et al. 2010, 2011) and sponges (Whalan et al. 2008). Changes in the geomorphology at a broader scale are also important in driving ecological patterns (Schneider et al. 1987; Jones et al. 2013a,b), primarily because of their effect on local hydrography (Duineveld et al. 2004, 2007). Additional factors that control food supply are also important, such as overlying productivity (Kahn et al. 2012), broadscale hydrographical patterns and local enrichments associated with the pycnocline (Huvenne et al. 2011). Habitat heterogeneity is well documented to increase beta and gamma diversity (Levin et al. 2001), but can also increase fine-scale habitat connectivity, which may be particularly important for species with limited dispersal, such as brooding gastropods. However, abundance of hard-substratum obligate species, such as stony corals, is typically increased by availability of suitable habitat (Mortensen et al. 2008).

The MAR around the Charlie-Gibbs Fracture Zone (CGFZ; $48-54^{\circ} \mathrm{N}$, Fig. 1) is a good place to assess spatial variation amongst assemblages of suspension-feeders (Table 1). This region is influenced by bathymetric barriers (the ridge axis and the CGFZ) as well as major deepwater circulation through the CGFZ (Shor et al. 1980; Read et al. 2010). The MAR has a terraced structure with areas of steep slopes $\left(>30^{\circ}\right)$ and cliffs, which account for around $5.7 \%$ of the total area, separating regions of flat and gently sloping soft sediments (Niedzielski et al. 2013; Priede et al. 2013). The initial assumption that differences in surface primary productivity either side of the sub-Polar Front would elicit differences in food supply at depth (Priede et al. 2013) has been abandoned owing to the range in particle provenance and similar flux rates north and south of the CGFZ (Abell et al. 2013). The bathymetric barrier created by the ridge itself does not influence the distribution of more motile species, such as fish or amphipods (Cousins et al. 2013; Horton et al. 2013), despite observed differences in amphipod community composition between the north and south (Horton et al. 2013). These barriers, although not necessarily restrictive to demersal nekton of macrofaunal polychaetes (Shields \& Blanco-Perez 2013), could potentially shape other megafaunal assemblages (Alt et al. 2013).

Video imagery is a well-established tool for characterizing benthic biology and has been used widely at the MAR (Alt 2012; Beazley et al. 2013; Bell et al. 2013; Gebruk \& Krylova 2013; Jones, Alt et al. 2013; Rogacheva et al. 2013). Here, ROV imagery was used to characterize the megafaunal assemblages and the sea-bed habitat of areas of steep slope on the MAR that had large areas of hard substratum. This study was carried out in order to describe relationships amongst sessile fauna, associated motile fauna and their physical environment at both broad scales, either side of the MAR and CGFZ, and at fine scales within transects. The following hypotheses were addressed in this study: (i) habitat type and availability, as observed in seafloor images, is indicative of species composition or diversity at the MAR and (ii) hard substratum megafaunal assemblages on the steep slopes of the MAR are different either side of the ridge or the CGFZ.

\section{Material and Methods}

\section{Data collection}

Four superstations were investigated at the MAR (Fig. 1, Table 1), northeast (NE), southeast (SE), northwest (NW) and southwest (SW) of the CGFZ, on the RRS James Cook cruise 048 (JC048) in 2010 (Priede \& Bagley, 


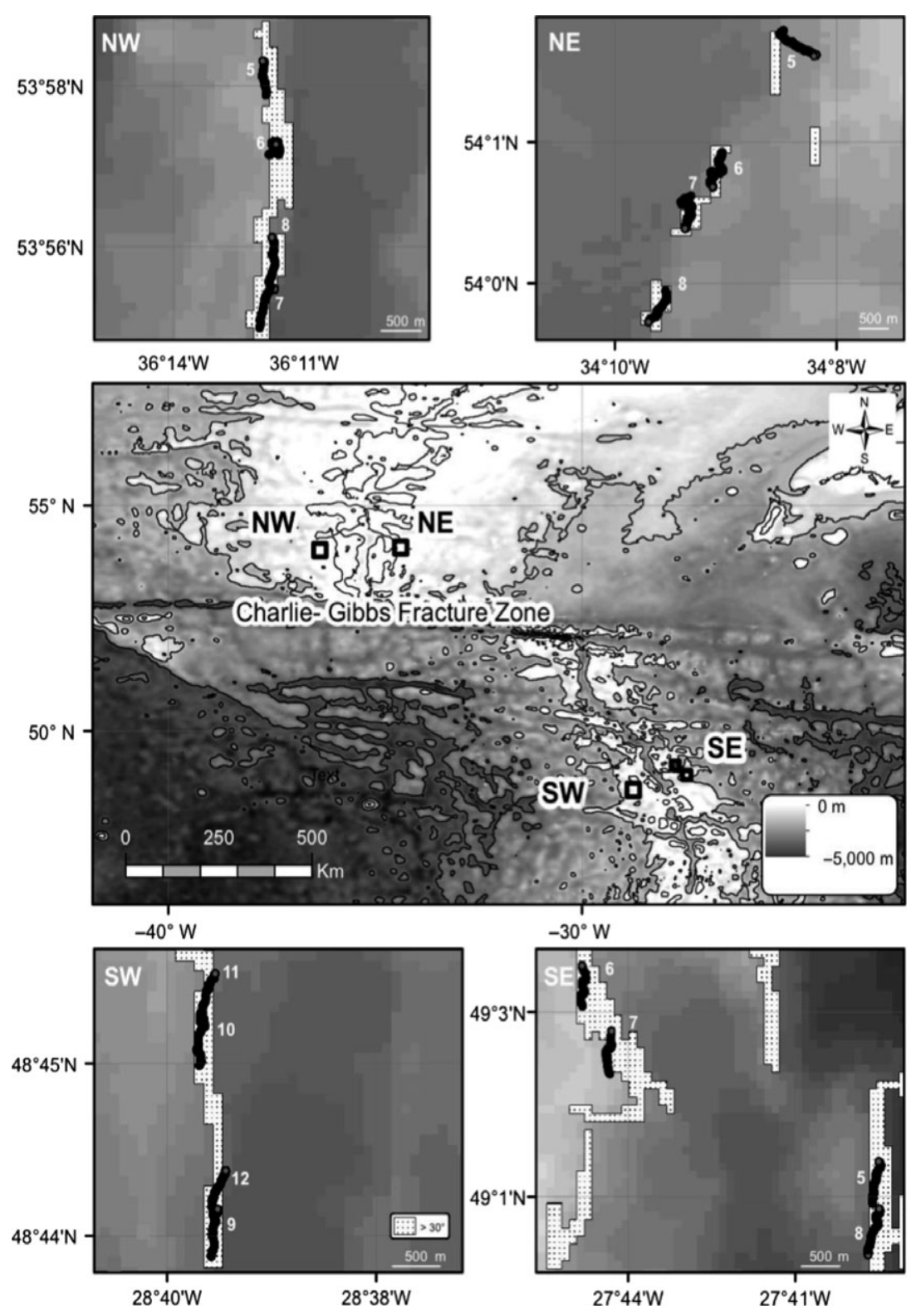

Fig. 1. Survey map: the central map shows the general sample area around the CharlieGibbs Fracture Zone, highlighting the four superstations (NW, NE, SW and SE). Individual superstation maps show the position of transects, together with the respective transect number (Table 1).
2010). High-definition video recordings $(1920 \times 1080$ pixels) were made with the ROV Isis along four 500-mlong transects at each superstation. Transects ran across steeply sloping $\left(>30^{\circ}\right.$ slope) sea floor at a target depth of $2500 \mathrm{~m}$ (Fig. 1). The position of each transect was selected at random using ARCGIS v. 10.0 (ESRI) within steep slope areas identified from shipborne multibeam bathymetry data (Kongsberg Simrad EM120) collected on RRS James Cook in 2007 (gridded with 50-m pixel resolution). Additional fine-scale multibeam bathymetry data were obtained by the ROV Isis (Niedzielski et al. 2013) during JC048 on nearby, but different areas of the MAR. Videos were collected using a forward-facing, high-definition fixed video camera (Insite Mini Zeus) and Hydragyrum medium-arc iodide lighting. Two parallel lasers were used as scale (100 mm apart). Sonardyne medium frequency ultra-short baseline navigation was used for absolute navigation coupled with more precise relative positioning using a 1200 $\mathrm{KHz}$ acoustic Doppler Velocity Log.

\section{Image analysis}

To quantify epibenthic megafauna, which are defined as specimens large enough to be clearly seen in sea-floor imagery (Gage \& Tyler 1991), still images (JPEGs) were extracted from high-definition videos at a rate of one 
Table 1. ROV video sampling locations around the Charlie-Gibbs Fracture Zone, showing the positions and depths of transects within the four superstations (NW, NE, SW and SE).

\begin{tabular}{|c|c|c|c|c|c|c|c|c|c|c|}
\hline \multirow{2}{*}{$\begin{array}{l}\text { superstation } \\
\mathrm{NE}\end{array}$} & \multirow{2}{*}{$\begin{array}{l}\text { transect } \\
05\end{array}$} & \multicolumn{2}{|c|}{ lat. start } & \multicolumn{2}{|c|}{ long. start } & \multicolumn{2}{|c|}{ lat. end } & \multicolumn{2}{|c|}{ long. end } & \multirow{2}{*}{$\begin{array}{l}\begin{array}{l}\text { average dive } \\
\text { depth }(\mathrm{m})\end{array} \\
2280\end{array}$} \\
\hline & & 53 & 57.86 & -36 & 12.49 & 53 & 58.12 & -36 & 12.40 & \\
\hline NE & 06 & 53 & 57.56 & -36 & 12.41 & 53 & 57.83 & -36 & 12.31 & 2293 \\
\hline NE & 07 & 53 & 56.45 & -36 & 12.50 & 53 & 56.72 & -36 & 12.40 & 2349 \\
\hline NE & 08 & 53 & 56.74 & -36 & 12.36 & 53 & 57.00 & -36 & 12.26 & 2420 \\
\hline NW & 05 & 54 & 2.15 & -34 & 8.60 & 54 & 2.41 & -34 & 8.49 & 2277 \\
\hline NW & 06 & 54 & 1.15 & -34 & 9.15 & 54 & 1.40 & -34 & 9.04 & 2293 \\
\hline NW & 07 & 54 & 0.79 & -34 & 9.39 & 54 & 1.05 & -34 & 9.28 & 2484 \\
\hline NW & 08 & 54 & 0.00 & -34 & 9.65 & 54 & 0.26 & -34 & 9.54 & 2476 \\
\hline SW & 09 & 48 & 43.83 & -28 & 39.61 & 48 & 44.09 & -28 & 39.47 & 2538 \\
\hline SW & 10 & 48 & 44.99 & -28 & 39.69 & 48 & 45.25 & -28 & 39.56 & 2331 \\
\hline SW & 11 & 48 & 45.25 & -28 & 39.69 & 48 & 45.51 & -28 & 39.56 & 2406 \\
\hline SW & 12 & 48 & 44.13 & -28 & 39.59 & 48 & 44.39 & -28 & 39.46 & 2565 \\
\hline SE & 05 & 49 & 1.31 & -27 & 41.07 & 49 & 1.57 & -27 & 40.94 & 2583 \\
\hline SE & 06 & 49 & 2.72 & -27 & 44.56 & 49 & 2.98 & -27 & 44.42 & 2095 \\
\hline SE & 07 & 49 & 2.25 & -27 & 44.24 & 49 & 2.51 & -27 & 44.11 & 2159 \\
\hline SE & 08 & 49 & 0.91 & -27 & 41.11 & 49 & 1.16 & -27 & 40.97 & 2601 \\
\hline
\end{tabular}

lat., latitude; long., longitude. frame per second. Owing to the irregular topography of the steep areas of the MAR, many images were not suitable for analysis. Sea-floor images were included if they met the following characteristics: (i) the image was not obscured by parts of the ROV or suspended particulate matter, (ii) both laser dots were clearly visible, (iii) the area of an image was $\geq 1$ and $\leq 10 \mathrm{~m}^{2}$ (to avoid selection bias for smaller species in images taken very close to the sea floor) and (iv) the image did not overlap with any other selected image.

The individual transects were used as independent sampling units, allowing true replication $(\mathrm{n}=4)$ within each superstation. Following the exclusion of unsuitable frames, the area of sea floor sampled in each transect was standardized by randomly selecting non-overlapping images until each transect had a total area coverage of $200 \mathrm{~m}^{2}\left( \pm 2 \mathrm{~m}^{2}\right)$, giving between 27 and 67 images per transect. A total of 686 images was analysed, covering an area of $800 \mathrm{~m}^{2}( \pm<0.5 \%)$ per superstation. Taxa were identified to the lowest possible taxonomic level in each frame, building on an existing species guide for the area (Alt 2012). Owing to the inherent lack of taxonomic detail with imagery, fauna could not be identified to species level (Sánchez et al. 2009); thus all fauna will be referred to here as morphospecies. In order to facilitate easy comparison with other studies, data on fauna were counted in ind. $\mathrm{m}^{-2}$ and then converted to ind. $\mathrm{ha}^{-1}$.

The distributions of hard rock and soft sediment were quantified using IMAGEJ (v. 1.47) by reformatting frames into binary images, using a threshold brightness value, defined manually frame-by-frame, that discriminated between light-coloured sediment and dark-coloured rock, and then calculating the percentage of the frame covered by each habitat (Rasband 2013). This technique can only describe the surface of the sea floor and does not discriminate between hard substratum with a thin veneer of sediment covering it and deeper soft sediments. Descriptive statistics (mean and SD) for rock coverage were generated for each transect and superstation, and compared with morphospecies richness.

\section{Statistical analysis}

Four statistical models were developed independently (Dobson \& Barnett 2008) to examine whether the rock coverage $(\%)$, megafauna density (no. ha ${ }^{-1}$ ), percentage cover of fauna (\%) and morphospecies richness (per transect) could be explained by the superstation. The percentage cover data (rock coverage and megafaunal percentage cover) were analysed using a Gaussian (ANOVA) model after arc-sin transformation (following a recommendation by Crawley 2007). For the megafauna density and morphospecies richness analyses a generalized linear model (GLM) was used. As the residual deviance (e.g. 12,000 for density) was greater than the residual degrees of freedom (e.g. 12 for density), indicating overdispersion, the GLMs were fitted with quasi-Poisson errors. Correlation between abundances of sessile and motile fauna was tested using a Spearman's rank test. Models were implemented using the glm, $\mathrm{lm}$ and ANOVA functions of the $\mathrm{R}$ package CAR (companion to applied regression; Fox \& Weisberg 2011) in the R programming environment ( $\mathrm{R}$ Development Core Team 2013). 


\section{Diversity and richness}

Unless otherwise specified, all subsequent analyses were conducted in the $\mathrm{R}$ environment. Species-accumulation curves were constructed (999 permutations) using ESTIMATES (v. 9.1.0) with 95\% confidence intervals (95\% CIs; Gotelli \& Colwell 2001; Colwell et al. 2004, 2012; Colwell 2013).

Evenness (J') was calculated from raw abundance data using the VEGAN (v. 2.0-8; Oksanen et al. 2013) package and compared amongst superstations with a one-way Kruskal-Wallis test. Pairwise beta diversity (Sørenson dissimilarity) was calculated in BETAPART (v. 1.2; Baselga 2010; Baselga et al. 2013) from presence-absence data, to calculate the proportion of shared species amongst superstations. Sørenson dissimilarity is given as $(b+c) /$ $(2 a+b+c)$, where $a$ is the size of the shared species pool and $b$ and $c$ are the sizes of the unique species pools at each site (Sørensen 1948; Baselga 2010).

\section{Community composition}

Owing to the high percentage of rare species $(70 \%$ of species were observed only once or twice and $<20 \%$ were observed more than four times), no transformation was applied and the raw abundance data were used to construct a Bray-Curtis similarity matrix. The community composition similarity matrix amongst superstations was compared using permutational ANOVA (PERMANOVA, 999 permutations; Anderson 2001). Community composition data were visualized using the hierarchical cluster (hclust, average linkage) and multidimensional scaling (metaMDS) routines in VEGAN (Oksanen et al. 2013). Cluster height was computed as a non-metric dissimilarity scale, based on Manhattan distance of Bray-Curtis similarity of community composition (Oksanen 2013). In order to reveal any structure within the taxonomic data (Clarke et al. 2006, 2008), a similarity profile routine (SIMPROF) test (10,000 permutations) was carried out on the BrayCurtis matrix.

\section{Results}

Description of the steep slopes of the Mid-Atlantic Ridge

The sea bed observed at steep areas of the MAR was a mixture of exposed outcrops or boulders interspersed with soft sediment. About $48 \%$ of the steep areas surveyed $\left(3200 \mathrm{~m}^{2}\right)$ were covered by rock, with coverage in individual images varying between $0 \%$ and $98 \%$ rock $(0-$ $82 \%$ for whole transects). Although the majority of transects ranged in cover between $35 \%$ and $65 \%$ rock, one transect (NE_05) lacked any rock (Table 2). Areas with homogenous substratum tended to be dominated by soft sediment (61 of 686 images had $>95 \%$ soft sediment, compared with six with $>95 \%$ rock). There was no significant difference in rock cover amongst superstations (ANOVA, $\mathrm{F}=1.278$, $\mathrm{df}=3,12, \mathrm{P}=0.326$ ).

\section{Faunal density and percentage cover}

A total of 927 individuals was counted, ranging between five and 154 individuals per $200 \mathrm{~m}^{2}$ transect and 55-405 individuals per superstation. Megafaunal density was six times higher in the north, with means of 4900 (NW $\pm 912 \mathrm{SE}, \mathrm{n}=4)$ and $5063(\mathrm{NE} \pm 1589 \mathrm{SE}, \mathrm{n}=4)$ individuals (ind.) $\mathrm{ha}^{-1}$ compared with 688 (SW $\pm 196 \mathrm{SE}$, $\mathrm{n}=4)$ and $938(\mathrm{SE} \pm 261 \mathrm{SE}, \mathrm{n}=4)$ ind. $\mathrm{ha}^{-1}$ in the south (Table 4). Differences north and south of the CGFZ were clearly significant [GLM (quasi-Poisson): Lratio $=33.685, \mathrm{df}=3, \mathrm{P}<0.01]$, but pairwise differences were not detected either side of the ridge. Megafaunal percentage cover was also significantly higher in the northern superstations (ANOVA $\mathrm{F}=3.70, \mathrm{df}=3,12$, $\mathrm{P}<0.05$; mean $0.97 \%$ in north) than the southern stations (mean 0.17\%). Pairwise comparisons revealed no significant differences in percentage cover either side of the MAR. Faunal density and percentage cover were not correlated with substratum availability (Spearman's rank; density: rho $=0.17, \quad \mathrm{P}=0.53$; percentage cover: rho $=0.12, \mathrm{P}=0.66)$. Faunal density and area coverage were lowest at transect NE_05 [500 ind. ha ${ }^{-1}(0.03 \%)$

Table 2. \% Rock coverage for each ROV transect and superstation, with their respective mean and range.

\begin{tabular}{|c|c|c|c|c|c|c|c|}
\hline \multirow{2}{*}{\multicolumn{2}{|c|}{$\begin{array}{l}\mathrm{NE} \\
\quad \text { rock cover }(\%)\end{array}$}} & \multicolumn{2}{|c|}{ NW } & \multicolumn{2}{|c|}{ SE } & \multicolumn{2}{|c|}{ SW } \\
\hline & & transect & rock cover (\%) & transect & rock cover $(\%)$ & transect & rock cover $(\%)$ \\
\hline 05 & 0 & 05 & 73 & 05 & 35 & 09 & 72 \\
\hline 06 & 38 & 06 & 35 & 06 & 55 & 10 & 42 \\
\hline 07 & 21 & 07 & 63 & 07 & 82 & 11 & 45 \\
\hline 08 & 69 & 08 & 60 & 08 & 38 & 12 & 37 \\
\hline range & 69 & range & 38 & range & 47 & range & 35 \\
\hline
\end{tabular}


compared with $5450-7700$ ind. ha ${ }^{-1}(1.2-2.1 \%)$ elsewhere in the NE], which was the only transect without exposed rock.

Densities of sessile and mobile (probably predominantly deposit-feeding fauna) epifauna were not correlated with each other (Spearman's rank: rho $=-0.13$, $\mathrm{P}=0.64$ ). Superstations north and south of the CGFZ had broadly comparable densities of mobile epifauna, ranging between 13 and 125 ind. ha ${ }^{-1}$ in the north, and 13 and 75 ind. ha ${ }^{-1}$ in the south. Two transects from the NW and one from the SE had no mobile epifauna in spite of a ready availability of soft sediment, particularly at SE_05 where hard substrata only accounted for 35\% of the transect area. SE_05 had a higher coverage of pteropod shells than elsewhere and this might have discouraged deposit feeders.

\section{Faunal composition}

Assemblages were dominated at all transects that had exposed rock by sessile fauna such as hexactinellids, demospongids and anthozoans (Table 3). Sessile species accounted for $60-100 \%$ of all fauna (based on density) across all transects with exposed rock and accounted for over $90 \%$ of the megafaunal abundance in nine transects. Poriferans dominated the northern superstations in percentage cover ( $97 \%$ of assemblage at NE and NW) and abundance ( $92 \%$ of assemblage at NE; $96 \%$ at NW). Demospongids were the most widespread taxon, being present at all transects that had exposed rock, followed by hexactinellids, which were present at all but one
(SW_12). Hexactinellids were common also in the south where they comprised characteristic assemblages with anthozoans and bryozoans. Demospongids were much less common in the southern superstations, but occurred at similar densities to bryozoans at the SW. Observed holothurians, malacostracans, ophiuroids, echinoids, tunicates, hydrozoans and crinoids tended to have a sitespecific distribution and together with fishes (usually Coryphaenoides spp.) and asteroids represented $<10 \%$ of the total density of fauna. Hydrozoa were only seen in the northern superstations, whereas crinoids, echinoids, tunicates and bryozoans were only observed in the south.

\section{Taxonomic richness and diversity}

A total of 95 morphospecies was observed, ranging between 28 and 45 morphospecies per superstation (see Table S1). Sessile (living on sediment or rock) species accounted for $95 \%$ of the abundance of the 927 individuals counted. Hexactinellids were the most taxonomically rich (36 morphospecies) at all superstations, ranging between seven and 24 morphospecies per superstation (despite never being the numerically dominant taxa). Anthozoans were the second richest morphospecies (14), followed by demospongids (12). Sessile fauna were mainly comprised of poriferans, alcyonaceans and bryozoans (but also other anthozoan species, and a tunicate), and made up 72 distinct morphospecies. The remaining 23 morphospecies comprised 17 echinoderms, three actinopterygii and three malacostracans. Hexactinellids accounted for around half of the total morphospecies richness in the northern super-

Table 3. The percentage contribution of major taxa to the total area cover and their density (ha ${ }^{-1}$ ), for each superstation. Note that poriferans (indet.) refer to spongiform individuals that were not positively identified as belonging to either the demospongids or the hexactinellids, using the species catalogue prepared by Alt (2012). Where means/SE given, $n=4$.

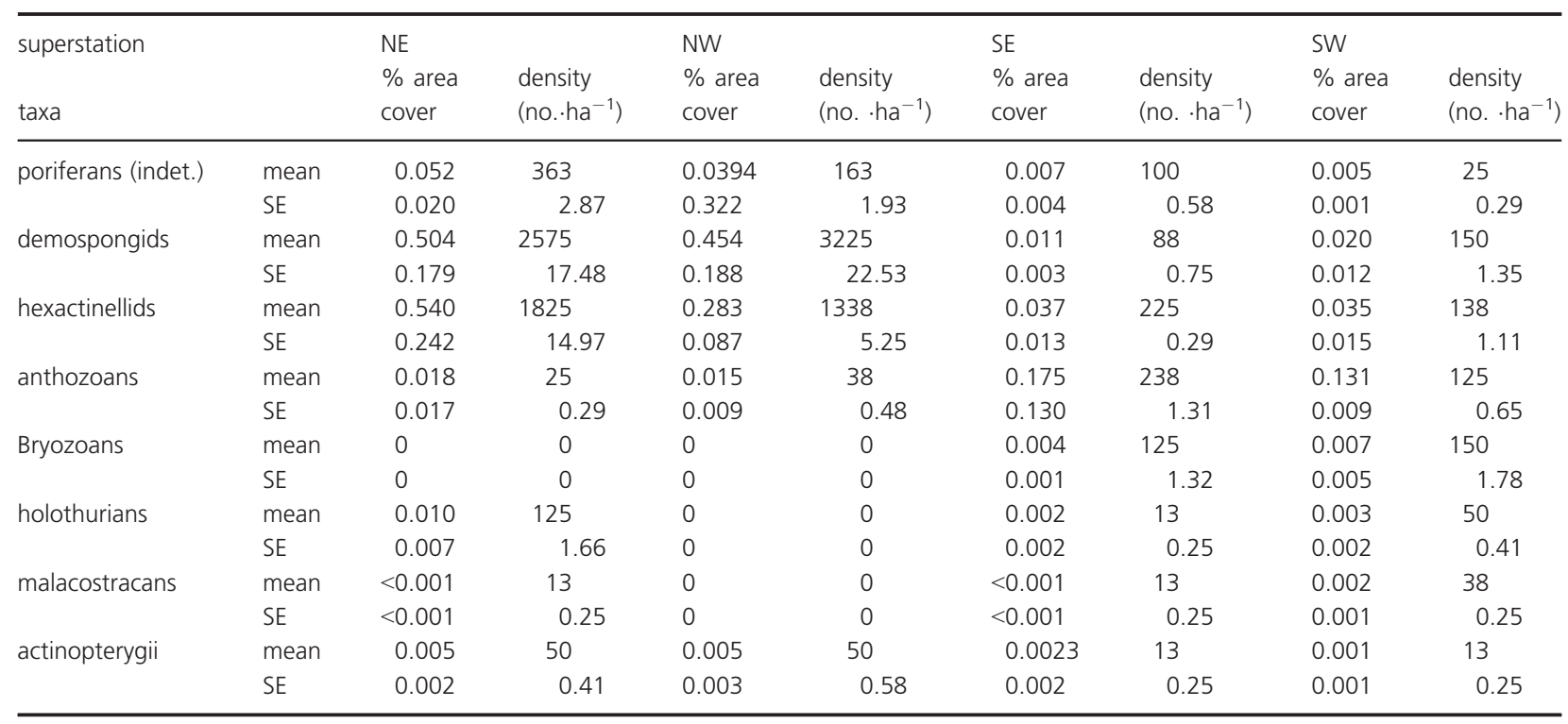


stations (49\% NE and 55\% NW). Demospongids were also more taxonomically rich in the north (nine to 10 morphospecies compared with four to five in the south), whereas more anthozoan morphospecies were found in the southern superstations (five to eight morphospecies compared with two to three in the north). The SE had the greatest range of morphospecies by major taxa, with representatives from all classes, except hydrozoans, which only occurred in the NW. The highest species richness occurred in transects that had between $35 \%$ and $43 \%$ rock coverage, independent of superstation. Hexactinellids appeared to favour areas of more heterogeneous substratum.

There was no significant difference in the absolute number of morphospecies found amongst superstations [GLM (quasi-Poisson): L-ratio $=6.83, \mathrm{df}=3, \mathrm{P}=0.08]$. However, species accumulation rates were much higher at the southern superstations, with the highest estimated species richness observed in the SE (Table 4 and Fig. 2). None of the species accumulation curves reached an asymptote, indicating that increased sampling effort would yield more species, particularly at the southern superstations. Differences in species richness were primarily driven by hexactinellids, with 22 (NE) and 24 (NW) morphospecies at the northern superstations, compared with seven (SW) and 12 (SE) at the southern superstations. Demospongid and anthozoan richness, by contrast, were comparable north and south of the CGFZ, although densities differed. All superstations showed a high level of evenness (J': 0.93-1.00, 1 being the highest possible even-

Table 4. Morphospecies diversity at each superstation, showing transect $(n=4)$ means and SEs. The estimated species numbers [ES $(n=54)]$ and number of morphospecies were based on superstation totals.

\begin{tabular}{|c|c|c|c|c|}
\hline & NE & NW & SE & SW \\
\hline \multicolumn{5}{|c|}{ faunal density (no. ha ${ }^{-1}$ ) } \\
\hline mean & 5063 & 4900 & 938 & 688 \\
\hline SE & 1588.68 & 911.73 & 260.91 & 196.19 \\
\hline \multicolumn{5}{|c|}{ density of sessile fauna (no. $\mathrm{ha}^{-1}$ ) } \\
\hline mean & 4788 & 4775 & 788 & 588 \\
\hline SE & 1676.48 & 937.75 & 198.30 & 207.54 \\
\hline \multicolumn{5}{|c|}{ density of motile fauna (no. $\mathrm{ha}^{-1}$ ) } \\
\hline mean & 275 & 125 & 125 & 100 \\
\hline SE & 105.08 & 94.65 & 62.92 & 20.41 \\
\hline \multicolumn{5}{|c|}{ percentage cover $(\%)$} \\
\hline mean & 1.13 & 0.81 & 0.25 & 0.09 \\
\hline SE & 0.43 & 0.23 & 0.14 & 0.3 \\
\hline \multicolumn{5}{|l|}{ evenness ( $\left.J^{\prime}\right)$} \\
\hline mean & 0.94 & 0.94 & 0.99 & 0.99 \\
\hline SE & 0.004 & 0.018 & 0.002 & 0.003 \\
\hline$E S(n=54)$ & 7.6 & 8.2 & 32.2 & 28.0 \\
\hline $\begin{array}{l}\text { number of } \\
\text { morphospecies }\end{array}$ & 45 & 44 & 40 & 28 \\
\hline
\end{tabular}

ness), with greater within-site variation in the north (Table 4). This reflected the large proportion of rare species present at the MAR.

Pairwise beta diversity analyses (Table 5) showed that the northern superstations were most similar in faunal assemblages, with $59 \%$ of species shared. The difference in composition was greater between the southern superstations, with just $42 \%$ of species shared (13 species). A greater species richness was observed at the SE site, with 40 identified morphospecies (from 75 individuals), compared with the SW site with only 28 morphospecies (from 55 individuals; Table 4). Porifera was the only taxon with the same number of morphospecies present at all superstations (one sp. indet., two demospongids and three hexactinellids). Several taxa were only found at one superstation. These represented $31-45 \%$ of the total morphospecies richness at each superstation. The SE had the most of these unique morphospecies (18), followed by the NW (15), NE (14) and SW (10). In total, 72 of the 95 morphospecies observed were only found north or south of the CGFZ. These differences were particularly obvious in some taxa. For example, 16 of the 17 echinoderm morphospecies were restricted to either the north or the south of the CGFZ.

\section{Community-scale description and analysis}

Community composition differed amongst all superstations (PERMANOVA, $\mathrm{F}=2.241$, $\mathrm{df}=3, \mathrm{P}=0.001$ ). The greatest differences in community composition were between superstations either side of the CGFZ (Fig. 3). The exceptions were transects NE_05 and SE_05, which were assigned to single sample clusters (SIMPROF, $\mathrm{P}=0.05)$. NE_05 was most different to all other transects, probably owing to the presence of a different habitat, caused by the absence of hard rock.

\section{Discussion}

Steep slopes cover an estimated $5.7 \%$ of the total area of the Northern MAR (Niedzielski et al. 2013; Priede et al. 2013). This study showed that hard substrata covered just under half $(48 \%)$ of this steeply sloping area, or $2.7 \%$ of the total area of the Northern MAR. The lack of distinction in substratum composition amongst superstations probably reflects the broadly similar geological origin and particle flux rates (Abell et al. 2013). Neither overall species composition nor the abundance of any major taxa (e.g. echinoderms, cnidarians or poriferans) were correlated with the available area of hard substrata. This stands in contrast to previous findings on corals at shallower depths of the MAR (Mortensen et al. 2008; Watanabe et al. 2009), which showed that abundance increases with 


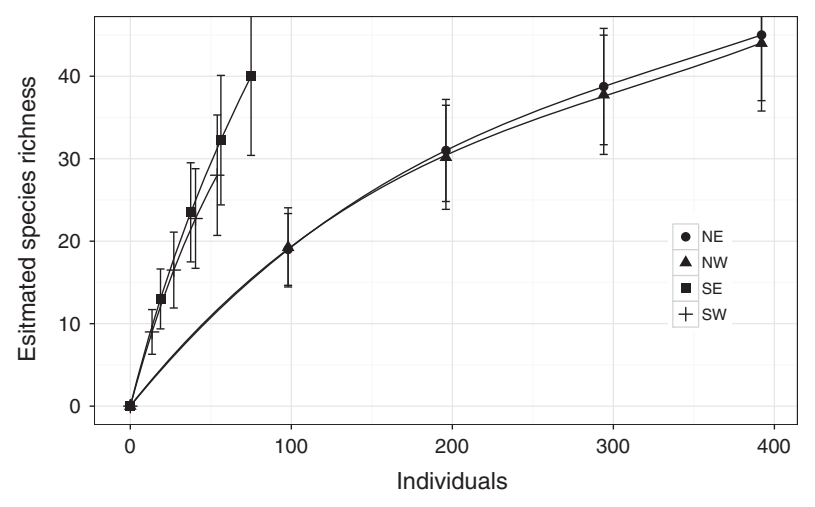

Fig. 2. Species-accumulation curves grouped by superstation. Error bars denote 95\% confidence intervals. Each line averaged from 999 permutations.

area of hard substratum availability. Habitat heterogeneity occurs at multiple scales and only the fine-scale patterns could be characterized in this study. Within the rocky areas of the steep slopes the variability in broad-scale habitat heterogeneity was high, from areas of smooth, vertical cliffs to patchy, rugose mixed habitat (Niedzielski et al. 2013). Although this variation appeared to occur similarly amongst the superstations, it was very difficult to quantify using the tools available and may have explained some of the changes in the fauna observed. Niedzielski et al. (2013) described different areas of steep slopes of the MAR, from ROV Isis fine-scale bathymetry, showing that steep slopes were a complex mix of sediment-covered slopes and sheer rock faces. These data are not directly comparable with our study as they are from different sections of the MAR but suggest that variation in habitat heterogeneity between areas could be high. Furthermore, the presence of tallus mounds at the bases of the steeper slopes and cliffs of the MAR (Priede et al. 2013) suggests that small, uncharacterized disturbance events, such as slope failures, regularly occur, potentially also influencing faunal patterns.

At a fine scale, substratum availability did not appear to limit megafaunal abundance at the MAR as there was a lot of rock uninhabited by megafauna, particularly in

Table 5. Sørenson dissimilarity index matrix of pairwise comparisons between superstations with geographical separation $(\mathrm{km})$ in parentheses.

\begin{tabular}{llll}
\hline & NE & NW & SE \\
\hline NE & - & & \\
NW & $0.41(137)$ & - & \\
SE & $0.51(679)$ & $0.47(777)$ & - \\
SW & $0.63(699)$ & $0.59(783)$ & $0.58(101)$ \\
grand dissimilarity index & 0.64 & & \\
\hline
\end{tabular}

the southern superstations where faunal density was much lower. Faunal density and species richness did not show a consistent relationship with the amount of hard substratum present. It would be expected, as found for poriferans, that species richness was highest in rocky areas with patchy sediment coverage, as mosaic habitats host both sessile and sediment-dwelling taxa (see NE; Fig. 4). However, in some groups, such as cnidarians, species richness increased with the amount of hard substratum (although there was always some soft sediment present). This relationship between substratum availability and species richness of cnidarians was consistent with that at shallower regions of the MAR (Mortensen et al. 2008), although our study covered a broader range of hard substratum availability. Attached fauna, which were probably predominantly suspension or filter feeders, dominated steep slopes at the bathyal depths studied here. This is typical in steep and often rocky environments (Witman et al. 2004), although not commonly investigated in the deep sea. Suspension feeders are reported to dominate at shallower regions of the MAR around the CGFZ (Mortensen et al. 2008). However, the
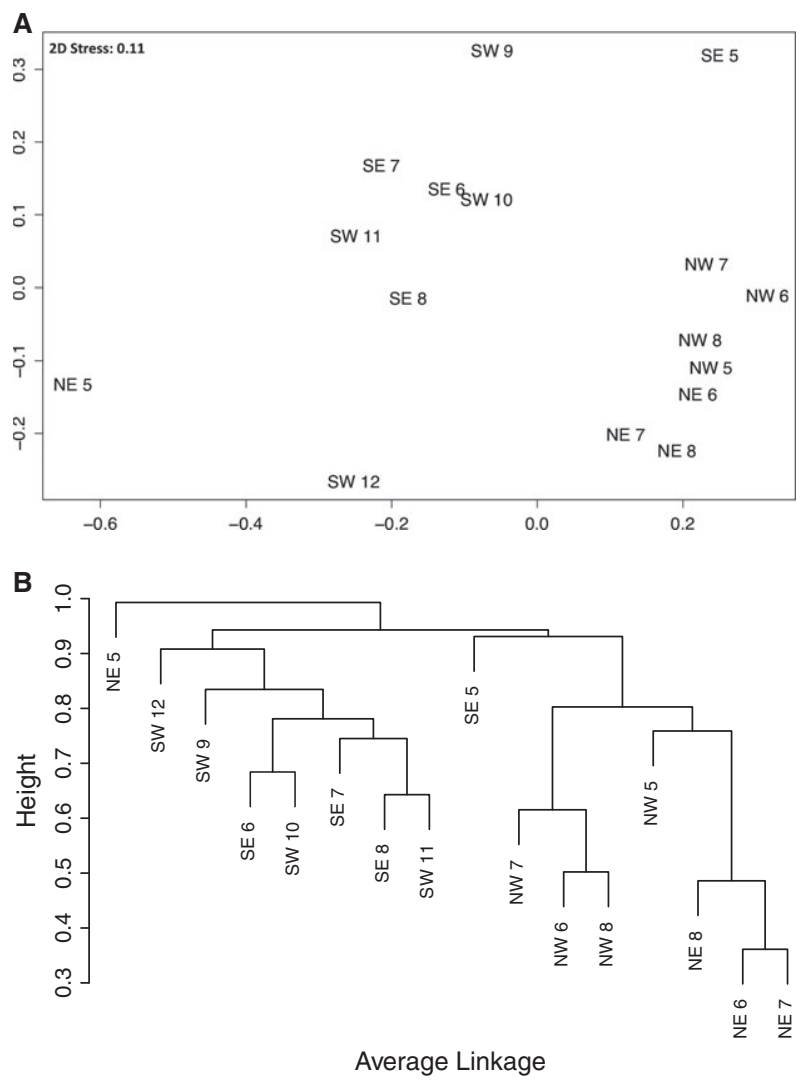

Fig. 3. (A): nmMDS ordination and (B): average-linkage cluster dendrogram (below), constructed from the Bray-Curtis similarity matrix. 

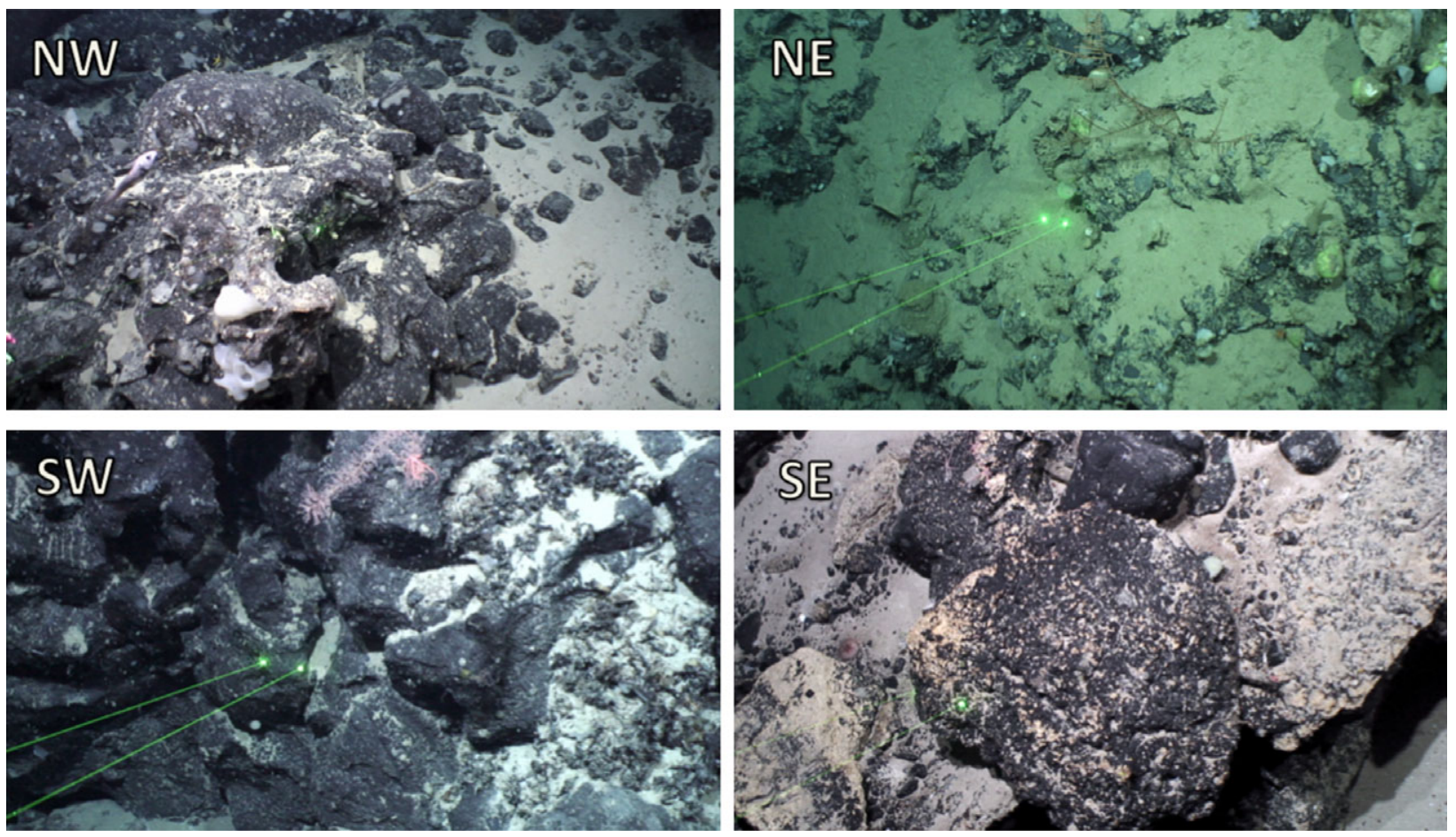

Fig. 4. Representative images of sea floor at the Mid-Atlantic Ridge. Rock cover (clockwise from NW) $69.6 \%, 34.5 \%, 59.1 \%$ and $81.8 \%$.

community composition here differed for the deeper sites, with more antipatharians and scleractinians present and fewer poriferans. At the CGFZ, in deeper waters, the assemblage composition (but not species composition) was more similar to our observations, with hexactinellids the most abundant taxon (Gebruk \& Krylova 2013).

\section{Broad-scale patterns in megafauna}

Community composition differed amongst all superstations, but the boundary provided by the CGFZ appeared to have a particular importance in separating assemblages. The differences in density on steep slopes north and south of the CGFZ were almost entirely driven by the abundance of attached fauna. Given the similarity in particle flux north and south of the CGFZ (Abell et al. 2013), it is unlikely that vertical transport of food was responsible for the differences observed. However, increased particle resuspension north of the CGFZ (Abell et al. 2013) could have supported a larger community of suspension or filter feeders. The dominant groups, hexactinellid and demospongids, showed the greatest differences in density north and south of the CGFZ. Sponges may have relatively limited dispersal owing to their reproductive mode of either asexual means or with lecithotrophic larvae (Woollacott 1993). Other common sessile fauna, such as cnidarians, may have longer larval durations and larger dispersal potential (van Praët et al. 1990) but were limited in their abundance at bathyal regions of the MAR. These potential changes in connectivity of taxa amongst the regions may go some way to explaining the patterns observed as density would be expected to increase if there are suitable supplies of propagules.

Barriers to dispersal around the CGFZ are probably a combination of the bathymetric barriers, represented by the fracture zone $(\mathrm{N}-\mathrm{S})$ and ridge axis $(\mathrm{E}-\mathrm{W})$, and the distances between superstations. Differences in community composition north and south of the CGFZ were greater than either side of the ridge and were probably enhanced by the increased space between superstations $(679-783 \mathrm{~km}$ and $101-137 \mathrm{~km}$, respectively). Although distances across the ridge were much smaller, turnover diversity was still relatively high, with the difference between the southern superstations ( $42 \%$ species shared) comparable to the difference observed north and south of the CGFZ.

Differences in composition amongst superstations were less clearly defined in this study than in others at the MAR (Alt 2012; Alt et al. 2013; Beazley et al. 2013), which may reflect the comparatively limited sampling size at the steep slopes. Nonetheless the data presented here show elements of the relationships exposed in the other surveys, such as the relatively high species richness at the SE (Alt et al. 2013) and the trends in hexactinellid, demospongid and anthozoan abundance north and south of the CGFZ (Alt 2012). Unlike other studies around the MAR, intra-superstation similarity was comparatively 
low, possibly as a result of small-scale patchiness. Similarities between the SW and elsewhere were particularly low (37-42\% species shared). However, the relatively low faunal abundance in the SW, coupled with the generally small sample size (five to 24 ind. per transect) may have reduced the ability to detect shared species.

\section{Conclusions}

Fine-scale habitat structure at steep slopes of the MAR was highly variable, ranging from sediment-covered slopes to sheer rock cliffs. The structure and density of epibenthic communities at steep slopes of the MAR were not controlled by fine-scale habitat availability, although there was evidence that areas of patchier rock coverage did enhance local species richness. Considerable differences in density were observed north and south of the CGFZ, driven largely by the abundance of attached fauna, particularly hexactinellids and demospongids. Density and community composition differed significantly amongst all superstations, with superstations either side of the ridge axis being more similar to each other than those north and south of the CGFZ, suggesting that bathymetric barriers are not as important as other factors in structuring megafaunal communities in rocky areas of the MAR.

\section{Acknowledgements}

This work was supported by the UK Natural Environment Research Council as part of the Ecosystems of the Mid-Atlantic Ridge at the Sub-Polar Front and CharlieGibbs Fracture Zone (ECOMAR) project (consortium grant number NE/C512961/1) and the Marine Environmental Mapping Programme (MAREMAP). Additional support was provided by the European Union Seventh Framework Programme (FP7/2007-2013) project Managing Impacts of Deep-seA reSource exploitation (MIDAS), grant agreement 603418. We thank the ships' companies of RRS James Cook, ROV operators, technicians and assistants, who contributed to this project, for their help and support. In particular, we would also like to thank Antonina Rogacheva and Andrey Gebruk for their taxonomic expertise that has contributed to this work. We are grateful to the associate editor Dr Jim Barry and two anonymous reviewers for their feedback.

\section{References}

Abell R.E., Brand T., Dale, A. C., Tilstone, G. H., Beveridge, C. (2013) Variability of particulate flux over the Mid-Atlantic Ridge. Deep Sea Research Part II: Topical Studies in Oceanography, 98, 257-268.
Alt C.H.S. (2012) On the benthic invertebrate megafauna at the mid-atlantic ridge, in the vicinity of the charlie-gibbs fracture zone. Ph.D Thesis, School of Ocean and Earth Science, University of Southampton, 237.

Alt C.H.S., Rogacheva A., Boorman, B., Hughes, J. A., Billett, D. S. M., Gooday, A. J., Jones, D. O. B. (2013) Trawled megafaunal invertebrate assemblages from bathyal depth of the Mid-Atlantic Ridge $\left(48^{\circ} \mathrm{N}-54^{\circ} \mathrm{N}\right)$. Deep-Sea Research II: Topical Studies in Oceanography, 98, 326-340.

Anderson M.J. (2001) A new method for non-parametric multivariate analysis of variance. Austral Ecology, 26, 32-46.

Auster P.J., Malatesta R.J., LaRosa, S. C. (1995) Patterns of microhabitat utilization by mobile megafauna on the southern New England (USA) continental shelf and slope. Marine Ecology Progress Series, 127, 77-85.

Baselga A. (2010) Partitioning the turnover and nestedness components of beta diversity. Global Ecology and Biogeography, 19, 134-143.

Baselga A., Orme D., Villeger, S. (2013) Package 'betapart'. cran.r-project.org.

Beazley L.I., Kenchington E.L., Villeger, S. (2013) Deep-sea sponge grounds enhance diversity and abundance of epibenthic megafauna in the Northwest Atlantic. ICES Journal of Marine Science, 70, 1471-1490.

Bell J.B., Jones D.O.B., Alt, C. H. S. (2013) Lebensspuren of the Bathyal Mid-Atlantic Ridge. Deep Sea Research Part II: Topical Studies in Oceanography, 98, 341-351.

Bo M., Bertolino M., Bavestrello, G., Canese, S., Giusti, M., Angiolillo, M., Pansini, M., Taviani, M. (2012) Role of deep sponge grounds in the Mediterranean Sea: a case study in southern Italy. Hydrobiologia, 687, 163-177.

Braga-Henriques A., Porteiro F.M., Bavestrello, G., Canese, S., Giusti, M., Angiolillo, M., Pansini, M., Taviani, M. (2013) Diversity, distribution and spatial structure of the coldwater coral fauna of the Azores (NE Atlantic). Biogeosciences, 10, 4009-4036.

Clark M.R., Rowden A.A., Schlacher, T. A., Guinotte, J., Dunstan, P. K., Williams, A., O’Hara, T. D., Watling, L., Niklitschek, E., Tsuchida, S. (2014) Identifying Ecologically or Biologically Significant Areas (EBSA): a systematic method and its application to seamounts in the South Pacific Ocean. Ocean \& Coastal Management, 91, 65-79.

Clarke K.R., Somerfield P.J., Chapman, M. G. (2006) On resemblance measures for ecological studies, including taxonomic dissimilarities and a zero-adjusted Bray-Curtis coefficient for denuded assemblages. Journal of Experimental Marine Biology and Ecology, 330, 55-80.

Clarke K.R., Somerfield P.J., Gorley, R. N. (2008) Testing of null hypotheses in exploratory community analyses: similarity profiles and biota-environment linkage. Journal of Experimental Marine Biology and Ecology, 366, 56-69.

Colwell R.K. (2013) EstimateS: Statistical estimation of species richness and shared species from samples. Version 9. Persistent URL $<$ purl.oclc.org/estimates $>$. 
Colwell R.K., Mao C.X., Chang, J. (2004) Interpolating, extrapolating and comparing incidence-based species accumulation curves. Ecology, 85, 2717-2727.

Colwell R.K., Chao A., Gotelli, N. J., Lin, S. Y., Mao, C. X., Chazdon, R. L., Longino, J. T. (2012) Models and estimators linking individual-based and sample-based rarefaction, extrapolation and comparison of assemblages. Journal of Plant Ecology, 5, 3-21.

Cousins N.J., Linley T.D., Jamieson, A. J., Bagley, P. M., Blades, H., Box, T., Chambers, R., Ford, A., Shields, M. A., Priede, I. G. (2013) Bathyal demersal fishes of Charlie-Gibbs Fracture Zone region $\left(49-54^{\circ} \mathrm{N}\right)$ of the Mid-Atlantic Ridge: II. Baited camera lander observations. Deep Sea Research Part II: Topical Studies in Oceanography, 98B, 388-396.

Crawley M.J. (2007). The R Book. Wiley-Blackwell, Chichester: 195-278.

Dobson A.J., Barnett A. (2008) An Introduction to Generalized Linear Models. Chapman \& Hall, Boca Raton, FL: 45-183.

Dorschel B., Wheeler A.J., de Haas, H. (2009) Cold-water coral mounds in an erosive environmental setting: TOBI side-scan sonar data and ROV video footage from the northwest Porcupine Bank, NE Atlantic. Marine Geology, 264, 218-229.

Duineveld G.C.A., Lavaleye M.S.S., Berghuis, E. M. (2004) Particle flux and food supply to a seamount cold-water coral community (Galicia Bank, NW Spain). Marine Ecology Progress Series, 277, 13-23.

Duineveld G.C.A., Lavaleye M.S.S., Bergmann, M. J. N., de Stigter, H. C., Mienis, F. (2007) Trophic structure of a coldwater coral mount community (Rockall Bank, NE Atlantic) in relation to the near-bottom particle supply and current regime. Bulletin of Marine Science, 81, 449-467.

Fox J., Weisberg S. (2011) An R companion to applied regression. California: SAGE Publications, $449 \mathrm{p}$.

Fox J., Weisberg S., Adler, D., Bates, D., Baud-Bovy, G., Ellison, S., Firth, D., Friendly, M., Gorjanc, G., Graves, S., Heiberger, R., Laboissiere, R., Monetter, G., Murdoch, D., Nilsson, H., Ogle, D., Ripley, B., Venables, W., Zeileis, A., The R Core Team (2013) Companion to applied regression. cran.r-project.org.

Gage J.D., Tyler P.A. (1991) Deep-Sea Biology: A Natural History of Organisms at the Deep-Sea Floor. Cambridge University Press, Cambridge: 61-114.

Gebruk A.V., Krylova E.M. (2013) Megafauna of the CharlieGibbs fracture zone (northern Mid-Atlantic Ridge) based on video observations. Journal of the Marine Biological Association of the United Kingdom, 93, 1143-1150.

Gotelli N.J., Colwell R.K. (2001) Quantifying biodiversity: procedures and pitfalls in the measurement and comparison of species richness. Ecological Letters, 4, 379-391.

Hareide N.-R., Garnes G. (2001) The distribution and catch rates of deep water fish along the Mid-Atlantic Ridge from 43 to $61^{\circ}$ N. Fisheries Research, 51, 297-310.

Horton T., Thurston M.H., Duffy, G. A. (2013) Community composition of scavenging amphipods at bathyal depths on the Mid-Atlantic Ridge. Deep Sea Research Part II: Topical Studies in Oceanography, 98B, 352-359.

Huvenne V.A., Tyler P.A., Masson, D. G., Fisher, E. H., Hauton, C., Huhnerbach, V., Le Bas, T. P., Wolff, G. A. (2011) A picture on the wall: innovative mapping reveals cold-water coral refuge in submarine canyon. PLoS One, 6, e28755.

Jones D.O.B., Alt C.H.S., Priede, I. G., Reid, W. D. K., Wigham, B. D., Billett, D. S. M., Gebruk, A. V., Rogacheva, A., Gooday, A. J. (2013a) Deep-sea surface-dwelling enteropneusts from the Mid-Atlantic Ridge: their ecology, distribution and mode of life. Deep Sea Research Part II: Topical Studies in Oceanography, 98, 374-387.

Jones D.O.B., Mrabure C.O., Gates, A. R. (2013b) Changes in deep-water epibenthic megafaunal assemblages in relation to seabed slope on the Nigerian margin. Deep Sea Research Part I: Oceanographic Research Papers, 78, 49-57.

Kahn A.S., Ruhl H.A., Smith, K. L. Jr (2012) Temporal changes in deep-sea sponge populations are correlated to changes in surface climate and food supply. Deep Sea Research Part I: Oceanographic Research Papers, 70, 36-41.

Kröger K.. (2013) OSPAR 2012 status report on the OSPAR network of marine protected areas. OSPAR Biodiversity Series.

Levin L., Etter R.J., Rex, M. A., Gooday, A. J., Smith, C. R., Pineda, J., Stuart, C. T., Hessler, R. R., Pawson, D. (2001) Environmental influences on regional deep-sea species diversity. Annual Review of Ecology and Systematics, 32, 5193.

Morris K., Tyler P.A., Murton, B., Rogers, A. D. (2012) Lower bathyal and abyssal distribution of coral in the axial volcanic ridge of the Mid-Atlantic Ridge at $45^{\circ} \mathrm{N}$. Deep Sea Research Part I: Oceanographic Research Papers, 62, 32-39.

Mortensen P.B., Buhl-Mortensen L., Gebruk, A. V., Krylova, E. M. (2008) Occurrence of deep-water corals on the MidAtlantic Ridge based on MAR-ECO data. Deep Sea Research Part II: Topical Studies in Oceanography, 55, 142-152.

Narayanaswamy B.E., Hughes D.J., Howell, K. L., Davies, J., Jacobs, C. (2013) First observations of megafaunal communities inhabiting George Bligh Bank, Northeast Atlantic. Deep Sea Research Part II: Topical Studies in Oceanography, 92, 79-86.

Niedzielski T., Høines Å., Shields, M. A., Linley, T. D., Priede, I. G. (2013) A multi-scale investigation into seafloor topography of the northern Mid-Atlantic Ridge based on geographic information system analysis. Deep Sea Research Part II: Topical Studies in Oceanography, 98, 231-243.

Oksanen J. (2013) Multivariate analysis of ecological communities in R: vegan tutorial. cran.r-project.org, Vegan: Community Ecology Package.

Oksanen J., Blanchet G.G., Kindt, R., Legendre, P., Minchin, P. R., O’Hara, R. B., Simpson, G. L., Solymos, P., Stevens, M. H., Wagner, H. (2013) Package 'vegan'. cran.rproject.org. 
Palardy J.E., Witman J.D. (2011) Water flow drives biodiversity by mediating rarity in marine benthic communities. Ecology Letters, 14, 63-68.

van Praët M., Rice A.L., Thurston, M. H. (1990) Reproduction in two deep-sea anemones (Actiniaria); Phelliactis hertwigi and P. robusta. Progress in Oceanography, 24, 207-222.

Priede I.G., Bagley P.M. (2010) RRS James Cook Cruise 048: ECOMAR Ecosystems of the Mid-Atlantic Ridge at the SubPolar Front and Charlie-Gibbs Fracture Zone. Cruise Report, OceanLab, University of Aberdeen, 26 May-3 July 2010.

Priede I.G., Bergstad O.A., Miller, P. I., Vecchione, M., Gebruk, A., Falkenhaug, T., Billett, D. S., Craig, J., Dale, A. C., Shields, M. A., Tilstone, G. H., Sutton, T. T., Gooday, A. J., Inall, M. E., Jones, D. O. B., Martinez-Vicente, V., Menezes, G. M., Niedzielski, T., Sigurethsson, Thorn., Rothe, N., Rogacheva, A., Alt, C. H., Brand, T., Abell, R., Brierley, A. S., Cousins, N. J., Crockard, D., Hoelzel, A. R., Hoines, A., Letessier, T. B., Read, J. F., Shimmield, T., Cox, M. J., Galbraith, J. K., Gordon, J. D., Horton, T., Neat, F., Lorance, P. (2013) Does presence of a mid-ocean ridge enhance biomass and biodiversity? PLoS One, 8, e61550.

Purser A., Orejas C., Gori, A., Tong, R., Unnithan, V., Thomsen, L. (2013) Local variation in the distribution of benthic megafauna species associated with cold-water coral reefs on the Norwegian margin. Continental Shelf Research, 54, 37-51.

Quattrini A.M., Ross S.W., Carlson, M. C. T., Nizinski, M. S. (2012) Megafaunal-habitat associations at a deep-sea coral mound off North Carolina, USA. Marine Biology, 159, 1079-1094.

R Development Core Team (2013) R: A Language and Environment for Statistical Computing. R Foundation for Statistical Computing, Vienna, Austria: http://www.Rproject.org/.

Rasband W.S. (2013)Image J. U.S. National Institutes of Health, Bethesda, MD, USA.

Read J.F., Pollard R.T., Miller, P. I., Dale, A. C. (2010) Circulation and variability of the North Atlantic Current in the vicinity of the Mid-Atlantic Ridge. Deep Sea Research Part I: Oceanographic Research Papers, 57, 307-318.

Robert K., Jones D.O.B., Tyler, P. A., Von Rooij, D., Huvenne, V. A. I. (2014) Finding the hot-spots within a biodiversity hotspot: fine-scale biological predictions within a submarine canyon using high-resolution acoustic mapping techniques. Marine Ecology, 36, 1256-1276.

Rogacheva A., Gebruk A., Alt, C. H. S. (2013) Holothuroidea of the charlie gibbs fracture zone area, northern Mid-Atlantic Ridge. Marine Biology Research, 9, 587-623.

Ross S.W., Quattrini A.M. (2007) The fish fauna associated with deep coral banks off the southeastern United States. Deep Sea Research Part I: Oceanographic Research Papers, 54, 975-1007.

Sánchez F., Serrano A., Ballesteros, M. G. (2009)

Photogrammetric quantitative study of habitat and benthic communities of deep Cantabrian Sea hard grounds.

Continental Shelf Research, 29, 1174-1188.

Schneider D.C., Gagnon J.-M., Gilkinson, K. D. (1987)

Patchiness of epibenthic megafauna on the outher Grand Banks of Newfoundland. Marine Ecology Progress Series, 39, $1-13$.

Shields M.A., Blanco-Perez R. (2013) Polychaete abundance, biomass and diversity patterns at the Mid-Atlantic Ridge, North Atlantic Ocean. Deep Sea Research Part II: Topical Studies in Oceanography, 98B, 315-325.

Shor A., Lonsdale P., Hollister, C. D., Spencer, D. (1980) Charlie-Gibbs fracture zone bottom water transport and its geological effects. Deep-Sea Research, 27A, 325-345.

Smith F., Witman J.D. (1999) Species diversity in subtidal landscapes: maintenance by physical processes and larval recruitment. Ecology, 80, 51-69.

Soltwedel T., Mokievsky V., Rabouille, C., Sauter, E., Volkenandt, M., Hasemann, C. (2013) Effects of experimentally increased near-bottom flow on meiofauna diversity and community structure in the Arctic Ocean. Deep Sea Research Part I: Oceanographic Research Papers, 73, 31-45.

Sørensen T.A. (1948) A method of establishing groups of equal amplitude in plant sociology based on similarity of species content, and its application to analyses of the vegetation on the Danish commons. Kongelige Danske Videnskabernes Selskabs Biologiske Skrifter, 5, 1-34.

Sun Z., Hamel J.F., Mercier, A. (2010) Planulation periodicity, settlement preferences and growth of two deep-sea octocorals from the northwest Atlantic. Marine Ecology Progress Series, 410, 71-87.

Sun Z., Hamel J.-F., Mercier, A. (2011) Planulation, larval biology, and early growth of the deep-sea soft corals Gersemia fruticosa and Duva florida (Octocorallia: Alcyonacea). Invertebrate Biology, 130, 91-99.

Wagner H., Purser A., Thomsen, L., Jesus, C. C., Lundälv, T. (2011) Particulate organic matter fluxes and hydrodynamics at the Tisler cold-water coral reef. Journal of Marine Systems, 85, 19-29.

Watanabe S., Metaxas A., Sameoto, J., Lawton, P. (2009) Patterns in abundance and size of two deep-water gorgonian octocorals, in relation to depth and substrate features off Nova Scotia. Deep Sea Research Part I: Oceanographic Research Papers, 56, 2235-2248.

Whalan S., Ettinger-Epstein P., Battershill, C., de Nys, R. (2008) Larval vertical migration and hierarchical selectivity of settlement in a brooding marine sponge. Marine Ecology Progress Series, 368, 145-154.

Wienberg C., Wintersteller P., Beuck, L., Hebbeln, D. (2013) Coral Patch seamount (NE Atlantic) - a sedimentological and megafaunal reconnaissance based on video and hydroacoustic surveys. Biogeosciences, 10, 3421-3443.

Witman J.D., Etter R.J., Smith, F., Paine, R. T. (2004) The relationship between regional and local species diversity in marine benthic communities: a global perspective. 
Proceedings of the National Academy of Sciences of the United States of America, 101, 15664-15669.

Woollacott R.M. (1993) Structure and swimming behaviour of the larva of Haliclona tubifera (Porifera: Demospongiae).

Journal of Morphology, 218, 301-321.

\section{Supporting Information}

Additional Supporting Information may be found in the online version of this article:
Figure S1. Morphospecies observed at steep slopes of the Mid-Atlantic Ridge. White bar scale bar $=10 \mathrm{~cm}$. Numbers refer to unique species ID in Table S1.

Table S1. Raw area and abundance measurements for each of the 95 morphospecies observed, summed by superstation (each superstation $=800 \mathrm{~m}^{2}$ ). 